\title{
Epidemiology of coronary heart disease. Lessons from North and South Belgium
}

\author{
J. V. JoOSSENS \\ M.D. \\ Leuven, Belgium
}

\begin{abstract}
Summary
Differences in food intake, smoking and drinking habits in the North and the South of Belgium have been studied with the aid of household data gathered by the National Institute of Statistics, Brussels, 1973-74. Consumption of sugar, vegetables, fruits, crude fibre and meat was almost identical between the regions. Consumption of bread, fish and salt intake were slightly higher in the North and alcohol consumption higher in the South. The major differences were located in fat consumption. Saturated fat as a percentage of dietary energy amounted to $15.8 \%$ in the North $v .18 .5 \%$ in the South; polyunsaturated fat was, respectively for the North and South, 7.9\% and $5.5 \%$. Dietary cholesterol intake was $320 \mathrm{mg} /$ day in the North against $400 \mathrm{mg} / \mathrm{day}$ in the South. The difference in serum cholesterol, calculated with the Keys formula, was $11.9 \mathrm{mg} \%$, a value totally consistent with the observed values.

The difference in saturated fat intake between the regions was almost entirely due to the difference of butter intake, thereby explaining why butter correlated so perfectly with mortality in different parts of Belgium. Similar correlations were found in France and Western Europe.

The mortality trends in both regions were compared with the available data on fat consumption over the last 15 years. Again a decreasing intake of saturated fat (less butter and less common (hard) margarine) was associated with a decreasing coronary, cardiovascular and total mortality in both the North and the South. The time-related decrease discussed in the second part was quantitatively similar to one obtained in the first part from geographical differences, making a spurious association extremely unlikely.

Similar dietary changes with identical results in terms of mortality have also been observed in the U.S.A. and Finland.
\end{abstract}

Aided by grants of the F.W.G.O., Brussels.

Address for reprints: Akademisch Ziekenhuis St-Rafael, Capucijnenvoer 33, B-3000, Leuven, Belgium.

\section{Introduction}

Belgium is interesting from an epidemiological point of view for 2 reasons. The first is the different eating patterns in the North and the South of the country (Joossens et al., 1977) and the second is the gradual change in terms of fat and salt intake (Joossens, 1980; Kornitzer et al., 1979) occurring in both parts of Belgium.

\section{The North-South difference}

During an extensive investigation in 1968-1969 of risk factors in the Belgian army, it was found by Van Houte and Kesteloot (1972) that serum choß esterol was higher in the South for all age group (Fig. 1). They also found a higher prevalence of coronary heat disease (CHD) in the South. Subsequent investigations among postmen (Vastesaeger et al., 1974) and industrial workers (Kornitzer et al., 1975) confirmed these observations. Van Houte and Kesteloot found no difference between regions for height, weight, blood groups, and smoking habits; a slightly higher blood pressure was recorded in the North.

Nothing was known in Belgium at the end of the 1960s about differences in food intake between the regions. Five independent enquiries done between 1970 and 1975 made it clear that butter consumption was 4 to 5 times higher in the South, whereas margarine intake was nealy twice as high in the North (Joossens et al., 1977; Joossens, 1979). All these enquiries, comprising household data from 11170 families, gave very consistent results (Fig. 2)* indicating that the serum cholesterol differences, previously found (Van Houte and Kesteloot, 1972) were most probably nutritional in origin.

The most detailed and expensive of these was a 12 month enquiry on the family budget (FB) and organized by the National Institute of Statistics (NIS) in Brussels from 1973 to 1974. A similar enquiry

\footnotetext{
*Figures 2-8 and Fig. 10 are based on data in Joossens, 1979, reproduced by kind permission of the editor of Acta cardiologica, Brussels.
} 
lasted 12 months from 1978 to 1979 but the results are not yet available. The primary aim of these enquiries was the calculation of the consumer price index, an exceedingly important index in a country where the income of every Belgian citizen is linked to it. It was carried out among 2613 families taken from a random sample of the Belgian population living in the North and the South. These families made fortnightly written reports of all costs (food, beverages, tobacco, household expenses, medical care, etc.) for one year. All details and results of the FB enquiry have been published (NIS, 1975; Joossens, 1979) and are summarized in Figs. 2-7. All data were calculated as consumer units, which are more or less equal to male adults (Joossens et al., 1977). Although this can be criticized (Wood, 1977) it is better than an average of the family per person. Since families tend to be larger in the North, the latter system would increase the South-North food gradient and the food-mortality correlation.

No important differences were seen for consumption of meat, sugar, fruits, vegetables, potatoes, fibre, potassium, calcium, phosphorus and iron. Consumption of fish, bread and salt was somewhat higher in the North. Alcohol, calculated per consumer unit in the family, was higher in the South.

Total energy intake was $11320 \mathrm{~kJ}$ in the North and $11870 \mathrm{~kJ}$ in the South. Total protein intake was $83 \mathrm{~g} /$ day and $82 \mathrm{~g} /$ day respectively, and carbohydrate

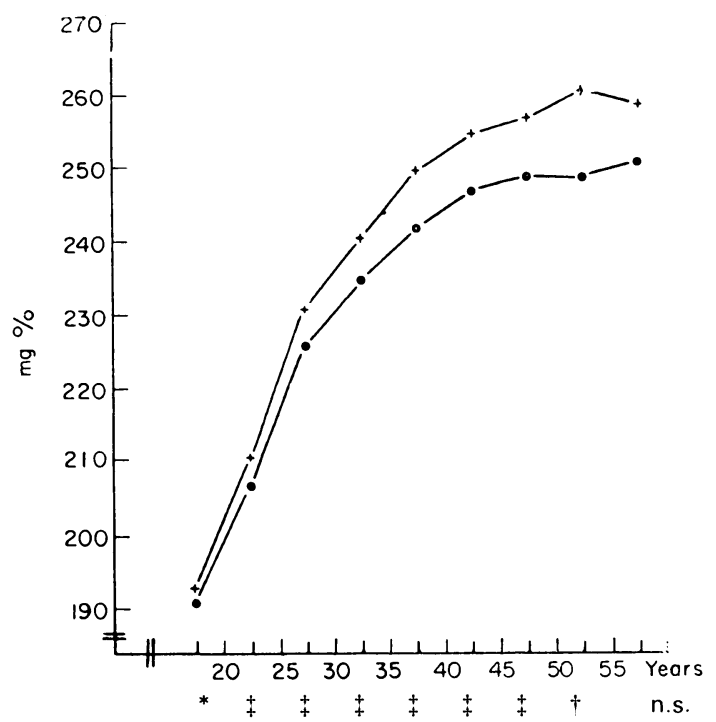

FIG. 1. Serum cholesterol concentration in inhabitants of northern and southern Belgium (adapted from Van Houte and Kesteloot, 1972). N $-025507: \mathrm{S}+-+=17248$. $* P<0.05,+P<0.01, \ddagger P<0.001$. consumption, at $309 \mathrm{~g} /$ day and $307 \mathrm{~g}$ /day, was very similar. Total fat intake was slightly lower in the North, $118 \mathrm{~g}$ as aginst $131 \mathrm{~g}$ in the South or $39.4 \%$ kJ v. $41 \cdot 7 \%$. The most important differences were in terms of saturated fat, $47 \mathrm{~g}$ against $58 \mathrm{~g}$ or $15.8 \%$ of dietary energy $v .18 .5 \%$, and polyunsaturated fat, $24 \mathrm{~g}$ against $17 \mathrm{~g}$ or $7.9 \%$ against $5.5 \%$.
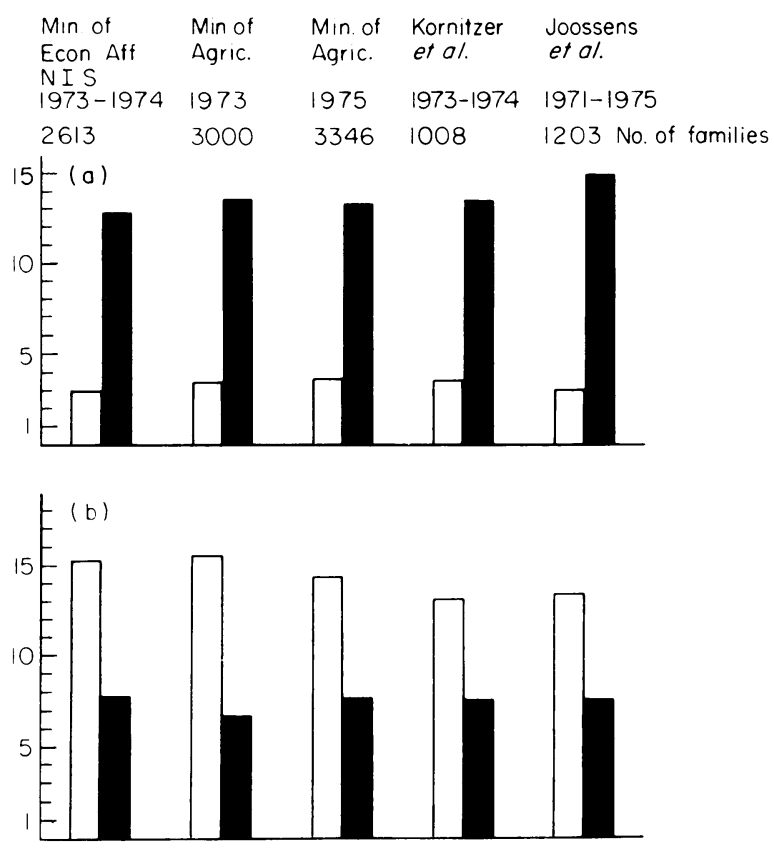

FIG. 2. The consistency of five independent food enquiries from Joossens, 1979 (Reproduced by kind permission of the Editor of Acta cardiologica, Brussels). = North $\mathbf{\square}=$ South.

Northern Belgium, southern Belgium. (NIS=National Institute of Statistics) (a) $\mathrm{Kg}$ butter/year/c.u. ( \pm one adult male), (b) $\mathrm{kg}$ margarine/year. (c.u. = consumer unit.)

Dietary cholesterol in the North amounted to $320 \mathrm{mg} /$ day and in the South $400 \mathrm{mg} /$ day. From these 3 sets of values it was possible to estimate a difference of $11.9 \mathrm{mg} / \mathrm{dl}$ in serum cholesterol according to the Keys formula, the South having the higher value. This was in accordance with the observed data (Fig. 1) and with data obtained later (Vastesaeger et al., 1974; Kornitzer et al., 1975). The saturated fat intake is illustrated in Fig. 7, indicating that the difference is almost entirely due to differences in butter consumption. Total saturated fat intake is $47.0 \mathrm{~g} /$ day in the North and 58.2 in the South, a difference of $11.2 \mathrm{~g} /$ day. For saturated fat from butter alone the difference is $12.7 \mathrm{~g}$ /day $(16.5-3.8$ $\mathrm{g}$ /day). 
No data on mortality existed in Belgium for the North and the South separately at the time the first results of the food enquiries became available. So it was with great eagerness that the first results were expected. They came for the year 1972 in May 1976, just before the European Congress of Cardiology in Amsterdam. They fitted almost entirely into the lipid heart hypothesis and were partially released at the Amsterdam meeting and published subsequently (Joossens et al., 1977). Data on other years for both regions became available only after the Joossens et al., 1977 publication (Joossens, 1979).

It came first as a surprise that total non-cancer mortality was also higher in the South, and gave an even better correlation with butter intake than coronary mortality. Afterwards it was possible to show that there was a perfect log-log correlation between coronary and non-cancer mortality from both sexes, using data from 12 standard countries (excluding Belgium) from 1952 to $1974, n=552$, $r=0.95$ (Joossens, 1980a). The regression equation was:

mortality/1000 from all causes except cancer $=$ 4.189 (coronary mortality/1000) ${ }^{0.589} \quad$ (Fig. 8).

This equation could then be used to detect major errors in classification of CHD in certain countries or regions. It could thus be shown that coronary mortality in the 45- to 64-year age group from France in 1974 was about 2.5 times higher than officially reported. The same was true for the South of

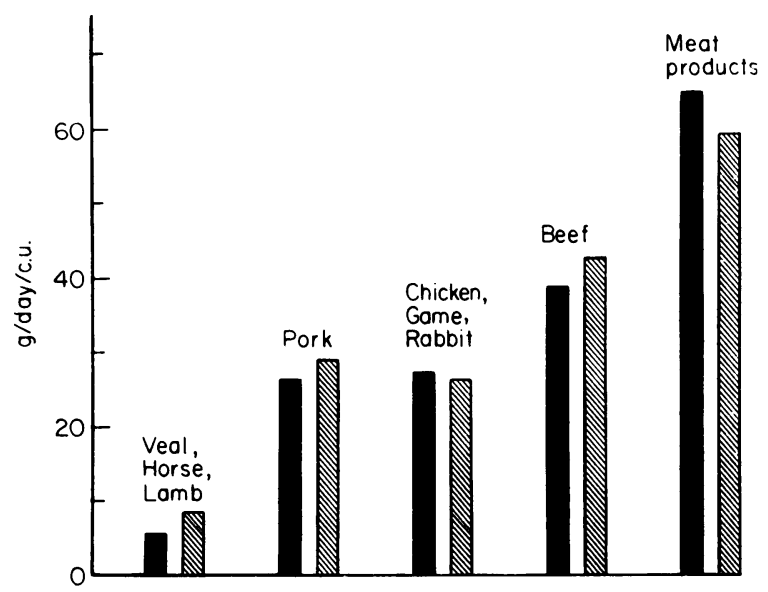

FIG. 3. Meat consumption in Belgium estimated from NIS data 1973-1974. Total consumption in the North ( $\square$ ) was $163 \mathrm{~g}$ and in the South $(\mathbb{N}) 164 \mathrm{~g}$. c.u.=consumer unit.
Belgium (1974) where reported values were probably 1.7 times too low in males. The reported values of the North (1974) were similar to those calculated (Fig. 8) (Joossens, 1979). The conclusion is that the real difference of coronary mortality between North and South was probably higher than reported.

The influence of coronary mortality on non-cancer mortality can be explained if one realizes that CHD is not limited in the population to the group dying from it. The final outcome of, e.g. an accident, a pneumonia or chronic bronchitis is also determined by the status of the coronary arteries. Diseased coronary arteries, although clinically not detectable, can lead, under these conditions, to a fatal outcome that would otherwise be avoidable. This is consistent with the observation that there was a significant correlation in males between violent deaths and butter intake in the 9 Belgian provinces in the 45 to 64 year age group, but not in the 15 to 24 year age group (Joossens, 1977).

Data on mortality for 1974 (unless stated otherwise all mortality rates are for males, age adjusted to 45-64 years/1000 inhabitants) between the North, the South and Brussels are given in Table 1. Wood (1977) states that cancer as a percentage of all causes is higher in the North namely $30.6 \%$ v. $24.8 \%$ i 1972. The implication has been made that cancer: mortality is higher in the North which could be the result of dietary change. This argument has been publicized by the dairy industry in both the U.K. and Belgium.

Although cancer as a percentage of total mortality is higher in the North, this does not mean that the actual cancer rate is higher. The cancer mortality rate is, in fact, slightly higher in the South for males and higher in the North for females in the period 1962-76 (Joossens, 1979). The average rate per 1000 ( \pm s.d.) for that period in males was 3.77 $(0.17)$ in the North $v .3 .94(0.17)$ in the South and $2.57(0.07)$ v. $2.42(0.09)$ in females. The significant per cent. increase for cancer in males over the same period was $11.2(3.5)$ in the South against 13.6 $(2 \cdot 1)$ in the North. No significant change of cancer mortality with time was observed in females from either region. Therefore no visible impact of different fat intake was observed on total cancer nor on the total cancer trends. If, however, these food patterns have an influence on non-cancer mortality it follows that a decreasing non-cancer mortality increases cancer as a percentage of total mortality. Similar observations can be made when comparing countries.

Thus coronary mortality in 1974 was lower in The Netherlands $(3 \cdot 28 / 1000)$ than in the U.S.A. $(5 \cdot 28 / 1000)$ and so was the total mortality $(10.4 v$. $14 \cdot 2 / 1000$ ). Cancer mortality was $3 \cdot 57 / 1000$ in The 
Netherlands against $3 \cdot 34 / 1000$ in the U.S.A., but the percentage of cancer as total mortality was 34.0 in the former against 23.5 in the latter.

Lung cancer mortality (Joossens, 1979) is very similar between the 2 regions and has increased in parallel fashion from 1962 to 1976 for both males and females. Smoking habits are more or less equal between the regions and no decrease in cigarette consumption was observed in Belgium before 1978.

Alcohol intake, mostly from wine, was higher in the South, but would probably have a beneficial influence in the South (St Leger, Cocharane and Moore, 1979), thereby decreasing the mortality gradient.

Sugar and fibre being equal cannot account for the difference either. Salt intake is slightly higher in the
North and, if anything, it would decrease the mortality gradient.

Since butter intake is the main difference between the North and the South, it is not so surprising to find that butter correlated perfectly with total mortality in males in the 9 provinces of Belgium. Using the same method of age adjustment, it was possible to compare the regression equation obtained in males in Belgium with those of France and those of other countries of the West.

The results for total mortality per thousand (TM/1000) were:
Belgium
$\left.\begin{array}{ll}\text { France } & n=8 ; r=0.84 ; 0.78+0.27 \\ \text { W. Europe } n=12 ; r=0.66 ; 0.68+0.29\end{array}\right\} \mathrm{kg} /$ year

$$
n=9 ; r=0.91 ; 0.79+0.27
$$
(Joossens, 1977; MacLennan and Meyer, 1977).

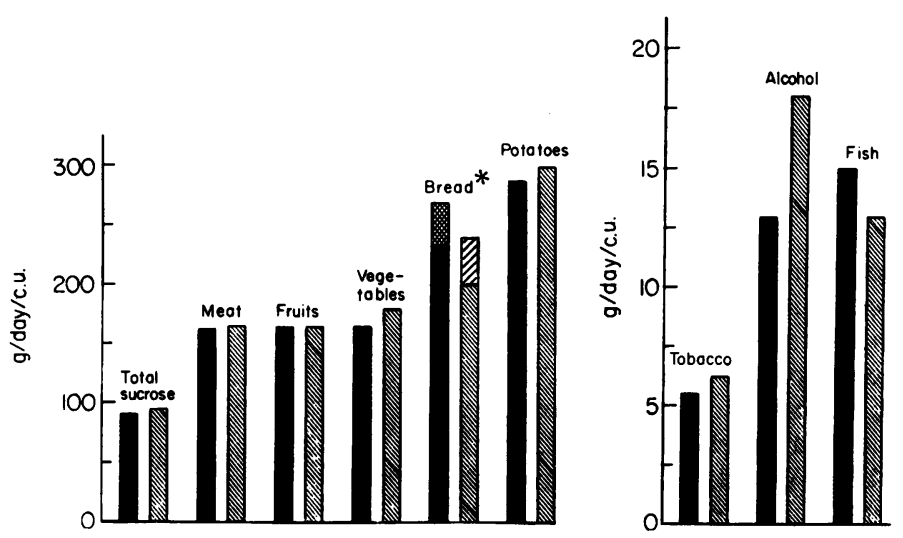

FIG 4. Intake per consumer unit (c.u.) in northern ( $\square$ ) and southern (1) Belgium estimated from National Institute of Statistics data 1973-1974*Upper part, cereals as bread.

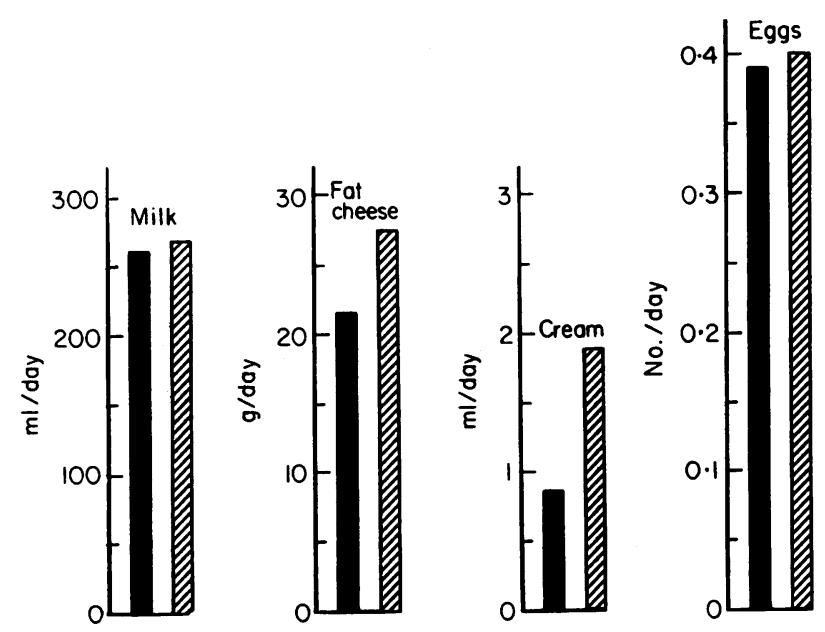

FIG. 5. Intake of dairy produce per consumer unit (c.u.) in northern ( $\square$ ) and southern (Welgium estimated from National Institute of Statistics data 1973-1974. 
The similarity of the regression lines is good evidence against a spurious origin and is in favour of a more fundamental relationship of saturated fat with overall mortality in middle-aged males.

It should be stated very clearly that the data do not implicate butter as the unique promoter of coronary atherosclerosis. They are just an illustration of the action of saturated fat. The only reason to single butter out is that it is the only factor which is a major difference between the regions. Saturated fat from common margarine, meat, etc., is probably just as dangerous, as was shown in the Seven Countries study (Keys, 1970).

To conclude this first part, it can be said that the only important differences between the North and the South of Belgium are those from saturated and polyunsaturated fat and from food cholesterol. They are qualitatively and quantitatively in accordance with the observed difference in serum cholesterol and in coronary morbidity and mortality. They are therefore totally consistent with the diet/heart hypothesis.

\section{Recent mortality trends in the North and the South of Belgium}

Astrup (1977), in a reaction to the paper by Joossens et al. (1977), stated quite correctly that timerelated changes in food intake and mortality are more important than geographical correlations. The geographical difference described in part I could theoretically also be due to a genetic difference, the North being less susceptible (Wood, 1977). Although so far there has been no evidence to support this

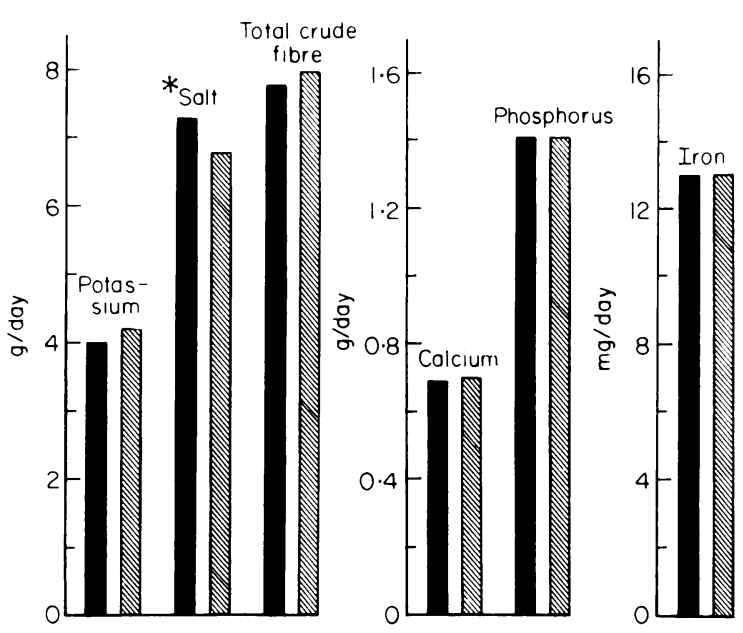

Fig. 6. Mineral and fibre consumption per c.u. in northern (ם) and southern $(\mathbb{Z})$ Belgium estimated from NIS data 1973-1974. *Salt added during cooking not included. point of view, it cannot be dismissed. It is therefore important to look at changes in food pattern in both regions and to changes in mortality.

Data on butter and margarine intake in Belgium as a whole have been available from the Ministry of Agriculture as household data from 3000 families (Nutelet, 1975). They show a decrease in butter consumption from 1955 to 1973 and an increase in margarine from 1955 up to 1968 , with a decrease in total margarine intake after 1968. Kornitzer et al. (1979) published household data on butter, common margarine, dietary margarine and oil intake for both regions from 1959 to 1976 . These were derived from 1008 families. They showed a rather steep decrease in butter intake from 1965. This was so for both regions, the butter intake being always higher in the South. After 1973 a plateau was observed. Butter intake decreased from $7.5 \mathrm{~kg} /$ person/year in 1965 to 3.6 in 1975 in the North and from $18.6 \mathrm{~kg}$ to 13.2 $\mathrm{kg} /$ person/year in the South.

Recent data for margarine alone are more complete than those from the Ministry of Agriculture cited in the preceding paragraph because common margarine and soft, salt-free dietary margarine have been tabulated separately. Common margarine intake is described as increasing up to 1968 with 8 decrease afterwards in both regions. Soft salt-free

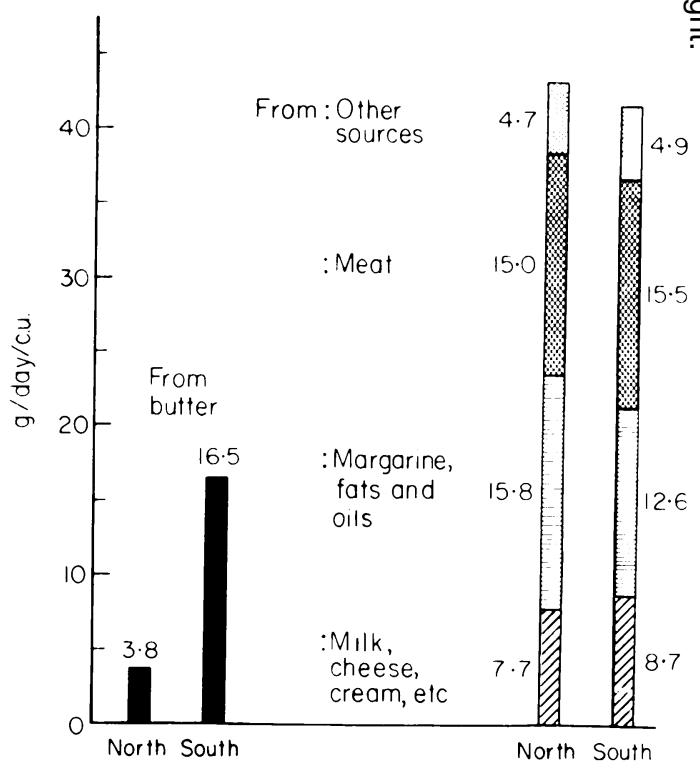

FIg. 7. Origin of the daily total intake of saturated fat. The results obtained can also be expressed as " of the total saturated fat intake per region. From butter: $8 \cdot 1$ v. $28 \cdot 3^{\circ}$; from other dairy products: $16.4 v \cdot 15.0^{\circ} \%$; from margarine, fats and oils: 33.6 v. $21.7^{\circ} \%$; from meat: $31.9 v$ v. $26.6^{\circ}$; from other sources: $10 \cdot 0$ v. $8 \cdot 4 \%$.

This indicates the areas where saturated fat intake has to be reduced. c.u. $=$ consumer unit. 
dietary margarine consumption was increasing sharply after 1968 and somewhat more in the North than in the South.

The only dissenting voice came from data from the EEC (1979). Butter consumption was $8.6 \mathrm{~kg} /$ person/year in 1965 and 1978. Margarine was reported as somewhat decreasing from, 13.2 to 11.6 $\mathrm{kg} /$ person/year.

'Foods moving into consumption' are notoriously less accurate than household data and were criticized in an EEC working group (Mitchell, 1977). They can lead to suspiciously high caloric intake (3441 cal in Belgium in 1973)(Kock-Henriksen, 1977). The consistency of the household data has been checked in 1974 (Fig. 1) with good results.

All-in-all those data indicate definite trends in the food pattern resulting in a decrease of saturated fat from butter and from the 'bad' margarines, together with an increase in polyunsaturated fat from dietary margarines and from corn, sunflower and soy-bean oil.
Coronary mortality and total cardiovascular mortality were declining in both the North and the South from 1969 to 1976; data on total morality were available from 1965 (Joossens, 1979). They declined in males in the South from $16 \cdot 6 / 1000$ in 1965 to $15 \cdot 0 / 1000$ in 1976 . In the North this went, respectively, from 12.9 to $11 \cdot 8 / 1000$. For females, the decrease was from $7 \cdot 1$ to $6 \cdot 1 / 1000$ in the North and from $7 \cdot 4$ to $6 \cdot 5 / 1000$ in the South for the same periods respectively. The correlation between mortality from all causes in males from 1965 to 1975 and observed in both regions separately (Joossens, 1979) with butter in $\mathrm{kg} /$ consumer unit/ year (Kornitzer et al., 1979) was again strikingly similar to the 3 already reported equations: $n=22$, $r=0.98 ; \mathrm{TM} / 1000=0.77+0.23$ butter $\mathrm{kg} /$ year. In this situation, over a period of 11 years, it is possible to exclude an important genetic influence.

The average slope of the 4 equations linking butter to mortality is $0 \cdot 265 / 1000 / \mathrm{kg}$ butter/year/consumer unit or $0.53 / 1000 / \mathrm{kg}$ saturated fat. $A$ decrease of

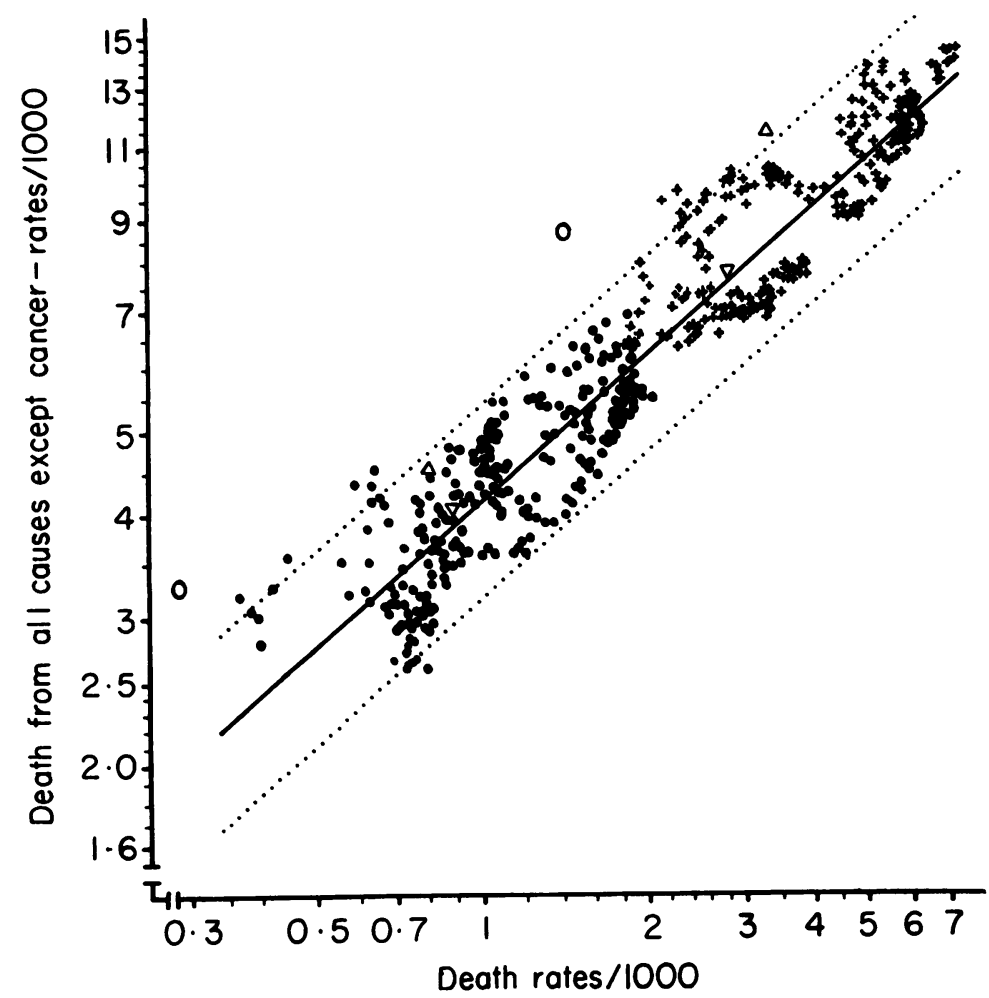

Fig. 8. The relationship of coronary death rates to all causes except cancer; age adjusted 45 to 64 years. from females. Data $(n=552)$ are from 12 Western countries with lowest death rates from 1952 to 1974 . The regression line is equal to $y=4.189 x^{0.589}$ with $r=0.95$. The $95 \%$ confidence intervals are indicated by the fine points. Data were drawn from France in $1974(0)$, the North $(\nabla)$ and South $(\triangle)$ of Belgium in 1974. In each case the higher value was from males, the lower from females. This shows that the coronary death rates in France are strongly underestimated, whereas those from northern Belgium fit perfectly in the overall picture. Those from males in the South are probably also too low. 
two thirds of the actual saturated fat intake would then result, if the extrapolation is correct, in a $50 \%$ decrease of the actual male total mortality. This would bring it to about $6 / 1000$, the actual value in the less susceptible part of Belgium, namely the females.

The time trends in both regions are at the origin of the reported decrease in coronary death rates in Belgium as a whole (Joossens, 1979). In Figs 9 and 10 the behaviour of total cardiovascular and of all causes minus cancer is given for 7 countries from 1968. The data illustrate the difference between countries (a) where life-style changes have been documented (the U.S.A., Finland and Belgium) and (b) where they have not. Saturated fat intake is not the only factor decreasing in Belgium. Salt consumption is also decreasing markedly: this may have contributed to the marked decrease of cerebrovascular mortality and of stomach cancer mortality in this country (Joossens, 1980).

Data gathered over 3 decades and ranging from molecular biology (Goldstein and Brown, 1977), to nutrition and to epidemiology (Blackburn, 1979; Keys, Grande and Anderson, 1974; Epstein, 1979), combined with the natural experiments occurring in the U.S.A., Finland and Belgium cannot be brushed away by a series of recent papers (Mann, 1977; Mitchell, 1977; McMichael, 1979; Werkö, 1979). Those authors did not provide any data showing the advantages or at least the neutral effects of eliminating saturated fats from the diet. They gave no evidence of any harm caused by increasing the intake of polyunsaturated fat. They only dwelt on the well known difficulties of proving a correlation between nutrition with serum cholesterol and of proving the beneficial effects of lowering saturated fats in prospective trials. They disregarded the evidence gathered in metabolic ward experiments on the influence of different types of fats on serum cholesterol (Keys et al., 1974).

The so-called 'final proof' of the beneficial effect of lowering cholesterol in the population is, in fact, unnecessary. The aim of preventive medicine is not to lower serum cholesterol but to prevent its rising in the first place. The importance of low (normal) cholesterol is clearly illustrated by the low CHD. rates in Japan and South Korea (Kesteloot et al., $\overrightarrow{\overrightarrow{\vec{S}}}$ 1979; Blackburn, 1979). It has been demonstrated in all prospective studies that a low (normal) serum $\underline{\underline{C}}$ cholesterol (less than $200 \mathrm{mg} / \mathrm{dl}$ ) has a low risk of $\frac{\overline{\bar{\rho}}}{\overline{2}}$ CHD. It may take a long time before this is realized $\mathbb{Q}$ at the population level, which is one more reason to take action now.

The totally consistent data obtained in Belgium $\overrightarrow{0}$ must impel us to reconsider the problem. No big $\overrightarrow{-}$ changes in mortality can be expected in such coun- $\omega$ tries as the U.K., Sweden and The Netherlands if no steps are taken to implement the recommendations 3 which have been made by their local scientific committees.

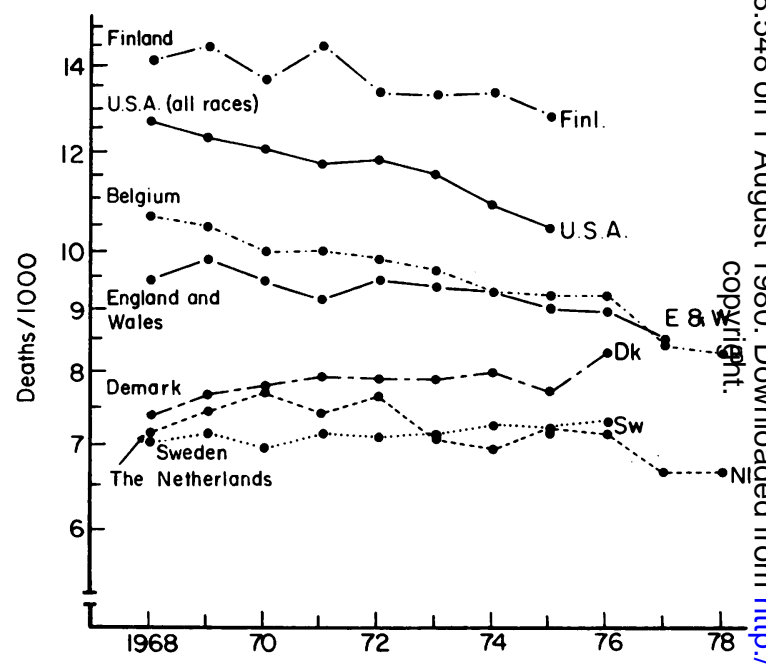

FIG. 9. Total cardiovascular mortality in males between $\tau$ 1968 and 1978 (age adjusted 45-64 years). The raw data were 3 provided through WHO, the NIS Brussels, the CBS the $\bar{\sigma}$ Hague, and the Registrar General, London. This implies no 3 responsibility whatsoever on their part. The data from Belgium in 1977 and 1978 are provisional. The slopes are logarithmic and can be compared to one another.

TABLE 1. Mortality/1000; age adjusted 45-64 years in Belgium 1974

\begin{tabular}{|c|c|c|c|c|c|c|}
\hline & \multicolumn{2}{|c|}{ North } & \multicolumn{2}{|c|}{ Brussels } & \multicolumn{2}{|c|}{ South } \\
\hline & Male & Female & Male & Female & Male & Female \\
\hline Coronary & $2 \cdot 85$ & 0.85 & $2 \cdot 42$ & 0.57 & $3 \cdot 55$ & 0.81 \\
\hline Cerebrovascular & 0.78 & 0.54 & 0.88 & 0.63 & 0.95 & 0.59 \\
\hline Total cardiovascular & $4 \cdot 71$ & $2 \cdot 01$ & $4 \cdot 29$ & 1.61 & $6 \cdot 18$ & $2 \cdot 28$ \\
\hline Total cancer & $3 \cdot 87$ & $2 \cdot 54$ & 4.05 & $2 \cdot 35$ & $3 \cdot 98$ & $2 \cdot 49$ \\
\hline Stomach cancer & 0.42 & $0 \cdot 15$ & $0 \cdot 29$ & $0 \cdot 13$ & 0.28 & $0 \cdot 11$ \\
\hline Lung cancer & $1 \cdot 56$ & $0 \cdot 12$ & $1 \cdot 45$ & $0 \cdot 14$ & $1 \cdot 64$ & $0 \cdot 11$ \\
\hline Senility and ill-defined diagnosis & 0.52 & $0 \cdot 28$ & $1 \cdot 37$ & 0.51 & 0.59 & 0.34 \\
\hline Infectious disease & $0 \cdot 10$ & 0.06 & $0 \cdot 22$ & $0 \cdot 12$ & $0 \cdot 21$ & 0.04 \\
\hline Violent death & 0.88 & 0.41 & 0.79 & 0.53 & $1 \cdot 33$ & 0.55 \\
\hline All causes & $11 \cdot 83$ & 6.40 & 13.08 & $6 \cdot 30$ & $15 \cdot 33$ & $7 \cdot 05$ \\
\hline
\end{tabular}


Translating into practical terms of diet means that there has to be a gradual change to eating more fish and less meat, thereby switching from fat to lean sources of protein such as poultry, game and veal.

Fat-containing dairy products should be replaced by fat-free ones. Natural sunflower, corn, soy-bean or olive oil together with unsalted soft dietary margarine should be used instead of butter, hard or semi-hard margarines and hardened shortening. The consumption of all kinds of vegetables including peas, beans, etc., the intake of cereals (preferably unsalted) and of all varieties of fruit should be encouraged. Of course, other risk-inducing factors such as smoking and lack of exercise should be discouraged at the same time.

The kinds of fats we are using today are derived mostly from the industrial exploitation of ruminants and from the hydrogenation of existing natural oils. This kind of nutrition, imposed upon us not by taste but by economic forces has no resemblance whatsoever to the food whereby mankind evolved. That food was derived from hunting and gathering. Hunting of free-living, lean animals and gathering of fruits and nuts gave a primitive nutrition low in saturated fat, low in sodium but high in potassium. It is not surprising that many people have become intolerant to the present way of eating.

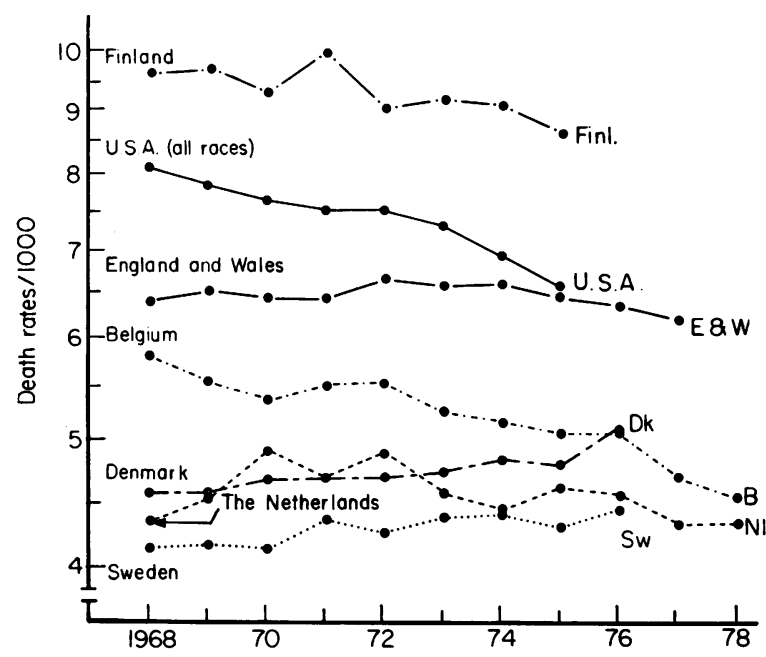

Fig. 10. All causes of death except cancer (age adjusted 45-64 years) in males between 1968 and 1978. The same origin of data as in Figure 8.

\section{References}

AstruP, P. (1977) Food and mortality in Belgium. Lancet, ii, 194.

Blackburn, H., Levy, R., Rifkind, B., Dennis, B. \& ERnst,
N. (1979) Diet and mass hyperlipidemia. In: Nutrition, Lipids and Coronary Heart Disease, p. 309. Raven Press, New York.

BlackBurN, H. (1979) Health effects of blood lipids: optimal distributions for populations. Epidemiological section report. Preventive Medicine, 9.

EEC (1979) Dairy Fats and Figures.

EPSTEIN, F.H. (1979) Nutrition, atherosclerosis and coronary heart disease. In: Atherosclerosis Reviews. Vol. 5. (Ed by Paoletti, R. \& Gotto Jr, A.M.), p. 149. Raven Press, New York.

GoldsteIn, L.J. \& BRown, M.S. (1977) Atherosclerosis: the low-density receptor hypothesis. Metabolism, 26, 1257.

Joossens, J.V. (1977) Food and mortality in Belgium. Lancet, ii, 603.

Joossens, J.V. (1979) Food pattern and mortality in Belgium. Acta cardiologica, 23, (Suppl.), 133.

Joossens, J.V. (1980b) Stroke, stomach cancer and salt. In: The Epidemiology of Arterial Blood Pressure. (Ed by Kesteloot, H. \& Joossens, J.V.) Martinus Nijhoff Medical Division, The Hague.

Joossens, J.V., Vuylsteek, K., Brems-Heyns, E., Carlier, J., Claes, J.H., De Backer, G., Graffar, M., Kesteloot, H., Kornitzer, M., Lequime, J., Pannier, R., Raes, A., VAN Houte, O., VAstesaeger, M. \& Verdonk, G. (1977) The pattern of food and mortality in Belgium. Lancet, i, 1069.

Kesteloot, H., Lee, C.S., Kegels, C., Lens, E. \& Joossens, J.V. (1979) An epidemiological survey of cholesterol and HDL-cholesterol in Korea and Belgium. Circulation, 59/60 (Suppl. 2) 66.

KeYs, A. (Ed.) (1970) Coronary heart disease in seven countries. American Heart Association Monograph, 29, New York.

Keys, A., Grande, F. \& ANDerson, J. (1974) Bias and misrepresentation revisited: perspective on saturated fat. American Journal of Clinical Nutrition, 27, 188.

Kock-HeNRIKSEN, P. (1977) Changes in eating habits over the last 20-30 years within the EEC. Influence on Health of Different Fats in Foods. EEC Information on Agriculture No. 40 (Part II-1), p. 1.

Kornitzer, M., De Backer, G., Dramaix, M. \& Thilly, C. (1979) Regional differences in risk factor distribution, food habits and coronary heart disease mortality and morbidity in Belgium. International Journal of Epidemio$\log y, 8,23$.

Kornitzer, M., Kittel, F., Ruskin, R.M., Degre, C., Dramaix, M. \& Thilly, C. (1975) Facteurs psychologiques et sociaux en relation avec les cardiopathies ischémiques. Archives des maladies du coeur, du sang et des vaisseaux, 68, 35.

Maclennan, R. \& Meyer, F. (1977) Food and mortality in France. Lancet, ii, 133.

McMichael, J. (1979) Fats and Atheroma: an inquest. British Medical Journal, 1, 173.

MANN, G.V. (1977) Diet-heart: end of an era. New England Journal of Medicine, 297, 644.

Mrtchell, J.R.A. (1977) Commentary. In: Influence on Health of Different Fats in Food. EEC Information on Agriculture No. 40 (Part III), p. 1.

National Institute of Statistics (1975) Family Budget Enquiry 1973-1974 Statistische studiën, Nos 38 and 41.

NutelET, R. (1975) Analyse van het boter- en margarineverbruik in België. L.E.I. Schriften no. 179/RR-149, Ministry of Agriculture, Brussels.

St Leger, A.S., Cochrane, A.L. \& Moore, F. (1979) Factors associated with cardiac mortality in developed countries with particular reference to the consumption of wine. Lancet, i, 1017. 
Van Houte, O. \& Kesteloot, H. (1972) An epidemiological survey of risk factors for ischaemic heart disease in 42,804 men. I. Serum cholesterol value. Acta cardiologica, 27, 527.

Vasi esaeger, M., Lefebvre, L., Graulich, P., Page, W. \& VANDERVEIKEN, F. (1974) Cholestérolémie, triglycéridémie et prévalence des cardiopathies ischémiques chez des postiers belges volontaires d'expression française et d'expression néerlandaise. Acta cardiologica, 29, 441.

Werkö, L. (1979) Diet, lipids and heart attacks. Acta medica scandinavica, 206, 435.

WooD, P.D.P. (1977) Food and mortality in Belgium, Lancet, ii, 873. 